\title{
Percepção dos gestores regionais de saúde sobre a política nacional de educação permanente em saúde no Estado do Maranhão-Brasil
}

\author{
Maria de Lourdes Carvalho' \\ Luís Alcoforado 2 \\ Ellen Rose Sousa Santos ${ }^{3}$
}

\section{RESUMO}

A Política Nacional de Educação Permanente em Saúde (PNEPS) surge da regulamentação do artigo 200 da Constituição Federal de 1988 e estabelece o princípio de ordenar a formação de recursos humanos na saúde visando mudanças na realidade de trabalho dos profissionais. Instituída em 2004, a PNEPS atribui aos gestores municipais de saúde a condução do planejamento regional, pactuação de recursos, definição de prioridades e apoio ao planejamento local da Educação Permanente em Saúde, (2004). Em 2017, buscando o fortalecimento e consolidação da PNEPS, o Ministério da Saúde desencadeou um processo de discussão nacional onde foram identificadas divergências na concepção dos gestores sobre educação permanente, fato considerado entrave para a consolidação da política. A partir disto, foi lançado o Programa para o Fortalecimento das Práticas de Educação Permanente em Saúde no Sistema Único de Saúde (PRO EPS-SUS). No Maranhão, foram realizadas 10 oficinas, contemplando as 19 regionais de saúde do Estado. O objetivo deste estudo foi identificar a percepção dos gestores sobre a Educação Permanente em Saúde. Tratou-se de um estudo qualitativo desenvolvido a partir das oficinas do PRO EPSSUS no Maranhão, das quais participaram 146 gestores. A coleta das

1 Doutoranda em Educação pela Universidade de Coimbra. Mestre em Ciências da Saúde pela Universidade Federal do Maranhão. Coordenadora de Pesquisa e Desenvolvimento em Saúde na Escola de Saúde Pública do Maranhão (ESP/MA). E-mail:mlourdinha@gmail.com

2 Doutor em Ciências da Educação pela Universidade de Coimbra. Coordenador do Mestrado em Educação e Formação de Adultos e Intervenção Comunitária. Membro da Coordenação do Doutorado em Ciências da Educação da Universidade de Coimbra- Portugal. E-mail: lalcoforado@fpce.uc.pt.

3 Mestre em Saúde da Família pela Rede Nordeste de Formação em Saúde da Família, nucleadora UFMA (RENASF/UFMA). Coordenadora do Curso na Escola de Saúde Pública do Maranhão (ESP/MA).E-mail: ellenrose.ss@gmail.com. 
informações se deu a partir do painel "Qual o seu entendimento sobre a Política Nacional de Educação Permanente em Saúde?" Percebeuse que eles ainda têm dificuldade na conceituação da Educação Permanente em Saúde e na diferenciação desta de outras ações do campo da Educação na Saúde, como a Educação Continuada e a Educação em Saúde.

Palavras-chaves: Educação permanente. Saúde. Política Pública

\section{Perception of regional health managers about the national policy for permanent education in health in the State of Maranhão- Brazil}

\section{ABSTRACT}

The National Policy for Permanent Education in Health (PNEPS) appears from the article 200 of the Federal Constitution 88 and established the principle of ordering the training of human resources in health that change the reality of the professionals' work. Established in 2004, a PNEPS assigns municipal health managers to conduct regional planning, agree on resources, define monitoring and support local planning for Permanent Health Education (BRASIL, 2004). In 2017, seeking to strengthen and consolidate the PNEPS, the Ministry of Health initiated a process of national discussion, where divergences were identified in the managers' analysis of permanent education, a fact considered an obstacle to policy politics (BRASIL, 2017b). Based on this, the Program for Strengthening Permanent Health Education Practices in the Unified Health System (PRO EPS-SUS) was launched. In Maranhão, 10 workshops were held, covering the 19 regional health regions of the State. The objective of this study was to identify the managers' perception of Permanent Education in Health. This was a qualitative study developed from the PRO EPS-SUS workshops in Maranhão, of which 146146 managers. Information was collected from the panel "What is your understanding of the National Policy for Permanent Education in Health?" It is noticed that they still have difficulties in the concept of Permanent Education in Health and differentiation among other actions in the field of Health Education, such as Continuing Education and Health Education.

Keywords: Permanent education. Health. Public policy. 


\section{Percepción de los gestores regionales de salud sobre la política nacional de educación permanente en salud en el estado de Maranhão-Brasil}

\section{RESUMEN}

La Política Nacional de Educación Permanente en Salud (PNEPS) surge de la reglamentación del artículo 200 de la Constitución Federal de 1988 y establece el principio de ordenar la formación de recursos humanos en la salud, con vistas a la mudanza en la realidad de trabajo de los profesionales. Instituida en 2004, la PNEPS atribuye a los gestores municipales de salud la conducción del planeamiento regional, pacto de recursos, definición de prioridades y apoyo al planeamiento local de la Educación Permanente en Salud (2004). En 2017, buscando el fortalecimiento y consolidación de la PNEPS, el Ministerio de Salud desencadenó un proceso de discusión nacional en que se identificaron divergencias en la concepción de los gestores sobre educación permanente, hecho considerado una traba para la consolidación de la política. A partir de ello, se lanzó el Programa para el Fortalecimiento de las Prácticas de Educación Permanente en Salud en el Sistema Único de Salud (PRO EPS-SUS). En Maranhão, se realizaron 10 talleres, contemplando las 19 regionales de salud del Estado. El objetivo de este estudio fue identificar la percepción de los gestores sobre la Educación Permanente en Salud. Se trató de un estudio cualitativo desarrollado a partir de los talleres del PRO EPS-SUS en Maranhão, de los cuales participaron 146 gestores. La recogida de informaciones se estableció a partir del panel “ ¿Cuál es su entendimiento sobre la Política Nacional de Educación Permanente en Salud?" Se percibió que ellos todavía tienen dificultades en la conceptuación de la Educación Permanente en Salud y en la diferenciación de otras acciones del campo de la Educación en la Salud, como la Educación Continuada y la Educación en Salud.

Palabras clave: Educación permanente. Salud. Política pública.

\section{Introdução}

A Política Nacional de Educação Permanente em Saúde (PNEPS) surge da regulamentação do artigo 200 da Constituição Federal brasileira de 1988, que além das atribuições pertinentes ao Sistema Único de Saúde, estabelece o princípio geral de "ordenar a formação de recursos 
humanos na área de saúde" (BRASIL, 1988, p.120). Importante dizer que para a compreensão desta política, deve existir o entendimento de que a educação deve ser pensada a partir dos contextos locais e de trabaIho para que possam ser garantidos os recursos educativos necessários, os espaços de vida suficientemente desafiadores e o acompanhamento a todos os que necessitam de ajuda para dar sentido às suas aprendizagens contínuas, promovendo o seu reconhecimento pessoal e social (ALCOFORADO, 2014)

Por outro lado, para um entendimento mais consensualizado de saúde é necessário lembrar que a Organização Mundial de Saúde (OMS) a define como completo estado de bem-estar físico, mental e social, e não somente ausência de afecções e enfermidades. A saúde é, portanto, um valor coletivo, um bem de todos, devendo cada um gozá-la individualmente, sem prejuízo de outrem, configurando-se em importante indicador de como funcionam os diversos grupos sociais e da efetividade das políticas públicas (MACHADO; LIMA; BAPTISTA, 2017).

Neste sentido, afirma-se que os profissionais de saúde inseridos na rede pública do Brasil compõem uma comunidade que desenvolve ações de saúde e de educação junto às pessoas atendidas pelo Sistema Único de Saúde (SUS), carecendo assim, de implementação da Educação Permanente em Saúde (EPS). Pela sua parte, a educação em saúde constitui um instrumento para a promoção da qualidade de vida e autonomia das pessoas, famílias e comunidades por meio da articulação de saberes técnicos e populares, de recursos institucionais e comunitários, de iniciativas públicas e privadas, superando a conceituação biomédica de assistência à saúde e abrangendo multideterminantes do processo saúde-enfermidade-cuidado (JUNIOR; ROCHA; FERRONATO, 2018).

A EPS é uma estratégia político-pedagógica que tem como objeto os problemas e necessidades oriundas dos processos de trabalho na saúde e a produção de conhecimento se dá no cotidiano do trabalho, envolvendo trabalhadores, gestores, usuários e a comunidade (BRASIL, 2004). O objetivo é a qualificação dos processos de trabalho em saúde, orientando-se para a melhoria do acesso, qualidade e humanização na prestação de serviços e para o fortalecimento do Sistema Único de Saúde no âmbito federal, estadual, municipal e local (BRASIL, 2018a). A Educação Permanente em Saúde pode, assim, fomentar mudanças na realidade de trabalho dos profissionais envolvidos à medida que fomenta a reflexão crítica sobre os problemas que comprometem a atenção à 
saúde, buscando fortalecer nos processos formativos não somente os conhecimentos técnico-científicos, mas também o planejamento do processo de trabalho (ALMEIDA et al., 2016).

A Política Nacional de Educação Permanente em Saúde (PNPES) brasileira, instituída em 2004, atribui aos gestores municipais de saúde, através das Comissões Inter gestores Regionais (CIR), a condução do planejamento regional, pactuação de recursos, definição de prioridades e apoio ao planejamento local da Educação Permanente em Saúde. Em nível local, fica atribuído aos gestores acompanhamento, monitoramento e avaliação das ações e estratégias, criando estruturas para sua implementação e participando do financiamento (BRASIL, 2004, 2007). É, então, indispensável que os gestores estejam preparados para assumirem a condução da política, não apenas incluindo as ações de Educação Permanente em Saúde nas agendas estratégicas dos municípios, mas também participando da elaboração e fortalecimento das ações e efetiva gestão dos processos de integração ensino-serviço-comunidade (FRANÇA et al., 2017; VENDRUSCOLO et al., 2018).

Para tanto, além de estarem sensibilizados sobre a importância estratégica da Educação Permanente em Saúde no processo de construção e consolidação do Sistema Único de Saúde (LEMOS, 2016), é indispensável que as ideias e pensamentos dos gestores em relação à EPS estejam bastante afinados. Acredita-se que a concepção dos gestores em relação à Educação Permanente em Saúde interfere diretamente na forma com que esta estratégia é organizada e implementada.

Neste sentido, em 2017, o Ministério da Saúde desencadeou um processo de discussão sobre a Política Nacional de Educação Permanente em Saúde com o objetivo de debater coletivamente estratégias para atualizar as portarias vigentes e elaborar propostas para o fortalecimento e consolidação do processo de implementação desta política. Percebeu-se, ao final do processo, que o principal problema não é o conteúdo da Política Nacional de Educação Permanente em Saúde e as diretrizes já existentes, mas a dificuldade no processo da sua implementação (BRASIL, 2017b). Identificou-se como uma das dificuldades a divergência na concepção da educação permanente por parte dos gestores. Vários estados destacaram a necessidade de desenvolver reflexões e debates sobre os conceitos de Educação Permanente em Saúde, considerando que ainda falta apropriação plena da concepção que fundamenta a política. Destacou-se, ainda, a necessidade de diferenciar conceitos de Educação 
em saúde, Educação permanente, Educação popular ${ }^{4}$, distinguindo-se, também, a Educação Profissional ${ }^{5}$ da Educação Permanente (BRASIL, 2017b).

A partir disto, tem-se o seguinte questionamento: Será que no Maranhão também existem divergências sobre a concepção dos gestores em relação à Educação Permanente em Saúde assim como identificado em âmbito nacional? De uma maneira consonante, o objetivo deste estudo é identificar a concepção dos gestores regionais de saúde sobre a Educação Permanente em Saúde no contexto dos municípios maranhenses. Baseado numa metodologia de recolha de informação resultante de reuniões com Gestores Regionais, o estudo indica a necessidade de novos debates sobra a EPS e de promover esclarecimentos e capacitações que colaborem com um "alinhamento conceitual" que facilite o processo de gestão de planejamento das ações de EPS.

O interesse por identificar qual a concepção dos gestores maranhenses sobre a Política Nacional de Educação Permanente emerge de uma pesquisa que e estuda Educação Permanente em saúde no estado do Maranhão: condições de implementação e perspectivas dos gestores de regionais de saúde.

Em nível de Brasil, a discussão para implementação da Política Nacional de Educação Permanente em Saúde tem ocupado espaço de grandes reuniões, surgindo o direcionamento para o reforço das ações de educação permanente na atenção básica. Neste sentido, o Ministério da Saúde criou o Programa para o Fortalecimento das práticas de Educação Permanente em Saúde (PRO EPS-SUS) na atenção básica e fez liberação de orçamento para todos os municípios e cada Estado ficou com a responsabilidade de organizar as ações de educação em saúde consolidando-as no Plano Estadual de Educação Permanente em Saúde. No Maranhão, a organização das ações se deu na Escola Técnica do SUS com o formato de oficinas/reuniões com gestores de saúde.

Diante da necessidade de desenhar as ações de educação permanente em saúde e de pesquisar a opinião de gestores de regionais

\footnotetext{
4 Prática educativa com foco na promoção, a proteção e a recuperação da saúde a partir do diálogo entre a diversidade de saberes dos trabalhadores da saúde e usuários, valorizando os saberes populares, a ancestralidade, movimentos populares a produção de conhecimentos e a inserção destes no Sistema Único de Saúde (BRASIL, 2017c).

5 Modalidade educacional de preparação dos indivíduos para a prática profissional, articulando os conhecimentos com a aplicabilidade destes no âmbito do trabalho (BERGER FILHO, 1999).
} 
sobre a Política Nacional de Educação Permanente em Saúde - primeiro objetivo específico da tese de doutoramento - a autora participou de todas as oficinas/reuniões utilizando o espaço de trabalho para fazer a atividade de pesquisa. Para realização das oficinas/reuniões, foi utilizada a metodologia ativa do tipo problematização para processar a participação dos gestores de saúde. Sendo assim, os gestores foram acolhidos, orientados sobre a metodologia de trabalho e em seguida participaram do seguinte questionamento: qual o seu entendimento sobre a Política Nacional de Educação Permanente em Saúde? Foi utilizada a metodologia de análise de conteúdo das respostas dos gestores. As oficinas para recolha de informações se deram na sede Escola Técnica do SUS do Maranhão.

Realizou-se uma análise dos painéis de respostas para identificar a concepção dos gestores com relação à Educação Permanente em Saúde. As respostas foram transcritas para uma planilha do Microsoft Excel e em seguida todas as respostas foram lidas e analisadas de maneira geral. Após a análise, as respostas foram agrupadas de acordo com os núcleos de sentido.

Identificou-se, posteriormente, que as respostas poderiam ser reorganizadas em seis núcleos de sentido, sendo estes: Educação Permanente em Saúde, Educação Continuada, Educação em Saúde, Contribuições gerais da Educação Permanente em Saúde, Sugestões e Desconhecimento sobre a Educação Permanente em Saúde. Ao todo foram realizadas 10 oficinas, contemplando todas as 19 regionais de saúde do Estado. Com participação de 146 gestores de regionais de saúde.

\section{Educação Permanente em Saúde no Brasil}

A reorientação do modelo assistencial em saúde no Brasil, em conformidade com os princípios do Sistema Único de Saúde, revela uma nova dinâmica de atuação das equipes de saúde com definição e compartilhamento de responsabilidades entre os serviços e a população (BRASIL, 2017a). De acordo com a Política Nacional de Atenção Básica em Saúde (2017a), a atenção básica em saúde é, tal como se define no Art $2^{\circ}$ :

[...] o conjunto de ações de saúde individuais, familiares e coletivas que envolvem promoção, prevenção, proteção, diagnóstico, tratamento, reabilitação, re- 
dução de danos, cuidados paliativos e vigilância em saúde, desenvolvida por meio de práticas de cuidado integrado e gestão qualificada, realizada com equipe multiprofissional e dirigida à população em território definido, sobre as quais as equipes assumem responsabilidade sanitária.

Ainda nesta publicação é possível perceber uma preocupação por parte do Ministério da Saúde em colaborar com a forma de organização dos serviços e produção de saúde e com a democratização do conhecimento em relação ao processo saúde-doença, sendo este último um dos pressupostos básicos relacionados à Educação Permanente em Saúde (BRASIL, 2004; FEUERWERKER, 2014; SILVA, 2015)

A Educação Permanente em Saúde é uma estratégia que visa fomentar mudanças na realidade de trabalho dos profissionais envolvidos à medida que fomenta a reflexão crítica sobre os problemas que comprometem a atenção à saúde, buscando fortalecer nos processos formativos não somente os conhecimentos técnico-científicos, mas também o planejamento do processo de trabalho (FRANÇA, 2017; ALMEIDA, et al., 2016).

Na visão de Ceccim e Ferla (2009, p.165):

Para produzir mudanças de práticas de gestão e de atenção, é fundamental dialogar com as práticas e concepções vigentes, problematizá-las - não em abstrato, mas no concreto do trabalho de cada equipe - e construir novos pactos de convivência e práticas, que aproximem o Sistema Único de Saúde da atenção integral à saúde.

Desta forma, a Educação Permanente em Saúde se destaca pela valorização do trabalho como fonte do conhecimento, articulação do cotidiano com o processo de construção do conhecimento e o desenvolvimento de ações educativas que promovam a transformação e melhoria da qualidade da atenção ofertada em uma dada realidade. Por isso, a educação deve ser trabalhada de maneira permanente e dinâmica, buscando construir espaços coletivos para a reflexão e avaliação, pondo o cotidiano do trabalho constantemente em análise (ALMEIDA, et al., 2016).

Posto isto, a educação permanente parte do pressuposto da aprendizagem significativa, onde se aprende e se ensina diariamente no âmbito do trabalho e quando o material a ser aprendido tem algum 
sentido para o educando e para a transformação das suas práticas profissionais cotidianas (FRANÇA et al., 2017; VENDRUSCOLO et al., 2018). Este processo tem como referência a reflexão crítica sobre as dificuldades do serviço, da comunidade, da gestão e do controle social e deverá promover a transformação das práticas profissionais e da própria organização do trabalho sendo estruturados a partir da problematização do processo de trabalho (CARDOSO et al., 2017).

Ao dialogar sobre a problematização da realidade do trabalho, a Educação Permanente em Saúde poderá se constituir como uma potente ferramenta para a gestão do trabalho na saúde, diferenciando-se da educação continuada não apenas conceitualmente, mas também com a representatividade com que esses momentos educativos atingem a realidade do trabalho (ANDRADE; LAPOLLI, 2018). Portanto, na Educação Permanente em Saúde, além da aquisição de conhecimentos, é possível promover espaços de autocrítica, tanto individual - dos profissionais de saúde - como coletiva sobre o trabalho, promovendo, concomitantemente, a democratização do saber nas organizações (CAVALCANTI; GUIZARDI, 2018; ANDRADE; LAPOLLI, 2018).

Além disto, o Ministério da Saúde (BRASIL, 2017b) recomenda que os profissionais da saúde instituam processos de Educação Permanente em Saúde suportados na reflexão sobre a conjuntura e as contingências institucionais, sob o ponto de vista ético e político, concebendo-os, assim, como um princípio constante de promoção e desenvolvimento integral e contextualizado da equipe, centrando-se nas fragilidades do processo de trabalho e dos problemas de saúde vivenciados pelas equipes de saúde de modo crítico e criativo. Em síntese, saberes, habilidades e valores deverão ser apropriados pela equipe no contexto do trabalho para que ela possa desempenhar suas atividades de forma satisfatória para todos os profissionais, bem como para as comunidades que integram e para quem trabalham (SILVA, 2015).

Assim, o planejamento das ações de Educação Permanente em Saúde pelas equipes deve ser sistematizado a partir do levantamento das necessidades das comunidades, dos profissionais e da gestão setorial. A seleção de conteúdos e os objetivos das ações devem contemplar as demandas de aprendizagem identificadas, enquanto a definição de métodos e técnicas de ensino devem possibilitar uma execução contínua de avaliação dos processos e dos resultados (BRASIL, 2017b), recomendando-se um diálogo com a organização territorial, pois o trabalho 
das equipes deve partir da compreensão das necessidades do território e da população sob a responsabilidade das equipes (BRASIL, 2017b). Defende-se ainda uma maior reflexão do profissional de saúde em seu trabalho vivo em ato para a própria autoanálise, e que é necessário do ponto de vista pedagógico abrir espaços relacionais para poder se falar e se implicar com isso (MERHY, 2007).

\section{Política Nacional de Educação Permanente em Saúde}

Em referência à questão da formação de recursos humanos para a saúde, o artigo 200 da Constituição Federal (CF) de 1988 atribui ao Sistema Único de Saúde a competência de "ordenar a formação de recursos humanos na área de saúde" e "incrementar o desenvolvimento técnico e científico da força de trabalho com atuação setorial" (BRASIL, 1988, Arto 200), determinando, com essa disposição legal, a responsabilidade dos gestores do SUS de formular e executar uma política de formação para os trabalhadores da saúde.

Com a promulgação da Constituição Federal e instituição das Leis no 8.080 e no 8.142 , de 1990, que regulamentam o Sistema Único de Saúde, definem-se as propostas de ordenação da formação de recursos humanos para a saúde em todos os níveis de ensino (BRASIL, 1990a, 1990b). Depois disto, várias propostas foram apresentadas para fortalecer a formação dos profissionais da saúde, entre elas a instituição da Política Nacional de Educação Permanente em Saúde, em 13 de fevereiro de 2004, através da portaria 198, implementando a EPS como estratégia para a formação e o desenvolvimento de trabalhadores para o setor.

Em 2007, a referida política foi complementada pela Portaria GM/Ministério da Saúde no 1.996 de 20 de agosto de 2007 que reforçou que os processos de qualificação dos trabalhadores da saúde devem ter como referência as necessidades das pessoas e das populações, da gestão setorial e do controle social em saúde, tendo como principal objetivo a transformação das práticas profissionais e da própria organização do trabalho a partir da problematização da atuação, sendo a atualização técnico-científica apenas como um dos aspectos da transformação das práticas e não seu foco central. A formação e o desenvolvimento englobam aspectos de produção de subjetividade, de habilidades técnicas e de conhecimento do Sistema Único de Saúde (BRASIL, 2007). Além disto, 
as diretrizes da Política (2007) atribuem a responsabilidade da sua condução ao Colegiado de Gestão Regional (CGR) que posteriormente, com a instituição do Decreto no 7.508 , passa a denominação de Comissão Intergestores Regionais (CIR) e as Comissões Permanentes de Integração Ensino-Serviço (CIES).

No que diz respeito às Comissões Intergestores Regionais (CIR), elas têm sob sua responsabilidade "instituir processo de planejamento regional para a Educação Permanente em Saúde, que defina as prioridades, as responsabilidades de cada ente e o apoio para o processo de planejamento local" devendo, para tal, ter o apoio das Comissões Permanentes de Integração Ensino-Serviço que participarão da "formulação, condução e desenvolvimento da Política Nacional de Educação Permanente em Saúde" nas locorregiões (BRASIL, 2007, p.1-2).

Estudos realizados para analisar a implementação da política nos municípios e estados brasileiros apontam evidências relevantes em relação às dificuldades neste processo, tais como: pouca articulação intergestores, trabalhadores, controle social e instituições de ensino; baixa implantação das Comissões Permanentes de Integração Ensino-Serviço regionais; participação incipiente dos gestores municipais; indefinição de parâmetros para construção dos projetos; ausência de avaliação acerca dos projetos desenvolvidos no que tange às suas desejadas mudanças nas práticas de formação, gestão e atenção na saúde; dificuldades na utilização dos recursos financeiros; dentre outras dificuldades (KRÜGER et. al., 2017; FRANÇA et al., 2017; DALFIOR et al., 2017).

Em 2017, na tentativa de desenvolver uma forma de enfrentamento para dificuldades com a implantação da Política Nacional de Educação Permanente em Saúde, o Ministério da Saúde promoveu um amplo debate em todo o país acerca do estágio de implementação dessa política (BRASIL, 2018b), constatando-se diversas dificuldades enfrentadas pela maioria dos Estados, Municípios e Distrito Federal. Das dificuldades, podem se destacar a suspensão do repasse dos recursos federais, a baixa capacidade de gestão da política, relacionada a dificuldades na gestão da PNEPS, a incipiente implementação da política, a confusão em relação a questões conceituais e o apoio incipiente prestado aos municípios e às estruturas regionais que, tendo recebido os recursos, tiveram dificuldades com a execução financeira (dados do diagnóstico DEGES/ SGTES 2015/16). 


\section{Metodologia e Procedimento}

Para o desenvolvimento da coleta de dados deste estudo, utilizou-se o cenário criado pelo Ministério da Saúde com o desenvolvimento do Programa para o Fortalecimento das práticas de Educação Permanente em Saúde (PRO EPS-SUS).

Após longo processo de discussão nas oficinas regionais e nacionais realizadas em 2017, envolvendo estados e municípios para avaliação do processo de implementação da Política Nacional de Atenção Básica em Saúde, o Ministério da Saúde lançou a Portaria n 3194, de 28 de novembro de 2017, criando o Programa para o Fortalecimento das Práticas de Educação Permanente em Saúde no Sistema Único de Saúde. O PRO EPS-SUS constitui-se em mais uma iniciativa da Secretaria de Gestão do Trabalho e Educação na Saúde (SGTES), do governo federal, com o propósito de fortalecer o processo de implementação da Política Nacional de Atenção Básica em Saúde nos estados, Distrito Federal (DF) e municípios brasileiros. O PRO EPS-SUS, tal como se afirma no Art. $2^{\circ}$, tem como objetivo:

[...] estimular, acompanhar e fortalecer a qualificação profissional dos trabalhadores da área da saúde para a transformação das práticas de saúde em direção ao atendimento dos princípios fundamentais do SUS, a partir da realidade local e da análise coletiva dos processos de trabalho (BRASIL, 2017b).

Com o PRO EPS-SUS, o governo federal destinou recursos financeiros aos estados, municípios e ao Distrito Federal (DF) que aderiram ao Programa, como uma forma de incentivar o desenvolvimento de ações de Educação Permanente em Saúde. Como contrapartida, os estados e Distrito Federal deveriam elaborar o Plano Estadual de Educação Permanente em Saúde e os municípios deveriam planejar e desenvolver atividades de EPS, voltadas às equipes da Atenção Básica.

Além disto, o PRO EPS-SUS previu o apoio técnico e institucional, oferecendo um conjunto de orientações para subsidiar os responsáveis pela gestão da Educação Permanente em Saúde nos estados e municípios, a fim de que pudessem elaborar seus planos e implementar as ações de EPS de forma planejada e organizada (BRASIL, 2018a).

No Maranhão, a execução do PRO EPS-SUS foi conduzida pela Escola Técnica do Sistema Único de Saúde/MARANHÃO “Dra. Maria Na- 
zareth Ramos de Neiva" (ETSUS/MA). Esta escola é vinculada à Secretaria Estadual de Saúde do Maranhão, integrando a rede pública estadual de educação e desenvolve processos formativos que atendam às demandas locais de formação dos trabalhadores que atuam no SUS no estado (MARANHÃO, 2003, 2012).

Foram realizadas oficinas com os representantes das secretarias de saúde e coordenação da atenção básica de todos os 217 municípios do estado para discutir sobre o PRO EPS-SUS e auxiliá-los na elaboração dos planejamentos das ações e estratégias para a Educação Permanente em Saúde em nível local e regional. Ao todo foram 10 oficinas, contemplando todas as 19 regionais de saúde do estado.

O período de realização foi de julho a agosto de 2018. Participaram 146 gestores de saúde ou representantes que eles indicaram para participarem da oficina.

No decorrer das oficinas, os participantes foram estimulados a discutirem sobre diversos aspectos da educação permanente, leitura e discussão sobre as portarias e a Política Nacional de Educação Permanente em Saúde, refletirem sobre as práticas de EPS desenvolvidas no território e a proporem atividades de EPS que poderiam compor os Planos Regionais de Educação Permanente em Saúde (PAREPS).

Para iniciar as discussões, o primeiro exercício foi refletir sobre o seguinte questionamento: Qual o seu entendimento sobre a Política Nacional de Educação Permanente em Saúde? O objetivo era diagnosticar o nível de compreensão dos grupos em relação à EPS e identificar os saberes prévios em relação à temática. Os painéis criados nesse momento foram utilizados como fonte de informações para este estudo.

Cada participante recebeu uma tarjeta para escrever uma frase curta que representasse a sua resposta ao questionamento. Em seguida, eles foram estimulados a construirem o mural das percepções dos gestores em relação à PNEPS. Durante a construção eles expressaram a justificativa para a resposta apresentada na tarjeta.

Realizou-se uma análise dos painéis para identificar a concepção dos gestores em relação à Educação Permanente em Saúde. As respostas foram transcritas para uma planilha do Microsoft Excel e em seguida todas as respostas foram lidas e analisadas de maneira geral. Após a análise, as respostas foram agrupadas de acordo com os núcleos de sentido.

Após a leitura de todas as tarjetas, identificou-se que as respostas poderiam ser reorganizadas em seis núcleos de sentido, sendo es- 
tes: Educação Permanente em Saúde, Educação Continuada, Educação em Saúde, Contribuições gerais da Educação Permanente em Saúde, Sugestões e Desconhecimento sobre a Educação Permanente em Saúde.

\section{Resultados e discussões}

Identificou-se que os 146 gestores que participaram das oficinas demonstraram concepções distintas em relação à Educação Permanente em Saúde, ou seja, somos levados a concluir que a concepção que eles construíram ainda é algo insipiente. Percebeu-se a inexistência ou não consenso (alinhamento conceitual) com relação à Educação Permanente em Saúde.

Gráfico 1: Distribuição da percepção dos gestores municipais de saúde do estado do Maranhão em relação à Educação Permanente em Saúde. São Luís, 2020.

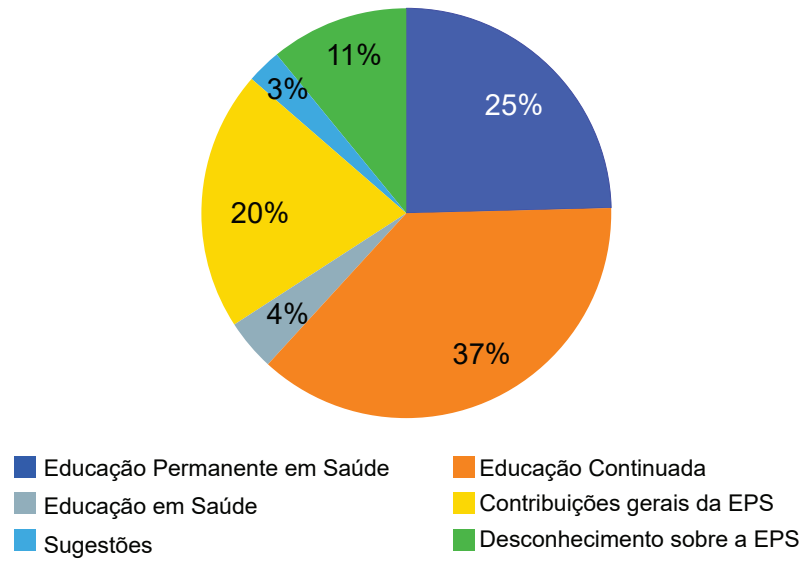

Fonte: Construção própria. Tarjetas utilizadas na oficina do PRO EPS-SUS realizadas pela ETSUS/MA. São Luís. 2020.

Vale lembrar que o Ministério da Saúde brasileiro concebe a Educação Permanente como:

conceito pedagógico no setor da saúde, para efetuar relações orgânicas entre ensino e as ações e serviços, e entre docência e atenção à saúde, sendo ampliado, na Reforma Sanitária Brasileira, para as relações entre formação e gestão setorial, desenvolvimento institucional e controle social em saúde (BRASIL, 2007, p. 1). 
Como é possível notar na análise dos núcleos de sentido, existe uma confusão na diferenciação da Educação Permanente em Saúde em relação às outras temáticas que tangem a educação na saúde. Nota-se que uma expressiva maioria dos gestores de saúde associou a Educação Permanente em Saúde a características da Educação Continuada ou até mesmo, embora com menor expressividade, com características da Educação em Saúde.

A Educação Continuada define-se como um conjunto de atividades educativas com o objetivo de atualizar e desenvolver conhecimentos no indivíduo (MARQUES, et al., 2018; BOMFIM, 2017). Devemos reconhecer a importância da Educação Continuada no sentido de que esta oferece um amparo às necessidades de conhecimento técnico e científico aos indivíduos que estão no serviço, garantindo que estes mantenham-se atualizados sobre os saberes necessários para o desenvolvimento de suas atividades e oportunizando uma participação mais eficaz no dia a dia do trabalho.

No entanto, a Educação Continuada é voltada para a concepção de educação como transmissão de conhecimento e valorização da ciência como fonte do conhecimento. Abrange a atualização e treinamentos direcionados para determinada categoria profissional de forma pontual, fragmentada, dissociada da realidade e sem promover articulação com os problemas identificado no trabalho (CARDOSO, 2019). Além disto, a Educação Continuada não promove articulação com a gestão setorial e nem com o controle social em saúde, focando apenas nas necessidades individuais (BOMFIM et al., 2017). Portanto, a indiscriminação por parte dos gestores em relação às práticas educacionais da Educação Permanente em Saúde e da Educação Continuada é bastante preocupante.

Na perspectiva da Educação Continuada, os gestores ainda entendem que a principal necessidade dos profissionais de saúde resume-se na realização constante de treinamentos pontuais. Todavia, devemos reforçar que a implementação da Educação Permanente em Saúde não é uma capacitação estanque e veio justamente para se contrapor a isto, buscando mudanças na prática do trabalho através de um processo contínuo e alinhado às necessidades do coletivo (LIMA; RIBEIRO, 2016).

Acredita-se que este entendimento por parte dos gestores pode estar associado a um baixo ou nenhum conhecimento destes em relação aos reais conceitos da Educação Permanente em Saúde e a uma extensão do modelo de formação acadêmico predominante no Brasil 
baseado no conhecimento técnico científico, focado em capacitações, ensinamentos, com a única finalidade de adequar os profissionais da saúde ao trabalho.

Nas oficinas regionais realizadas pelo Ministério da Saúde em 2017 para avaliar a implementação da Política Nacional de Educação Permanente em Saúde no âmbito nacional, identificou-se uma realidade similar a esta que estamos demonstrando neste estudo. A análise do modelo de Educação Permanente em Saúde implementado apontou a permanência de um modelo de formação tradicional, caracterizado pela reprodução de cursos e atividades voltadas às categorias profissionais isoladas em detrimento de um modelo inovador que leve em conta o trabalho em equipe, a integralidade da atenção (BRASIL, 2017b).

Outra confusão identificada a partir da análise das respostas foi a associação de características da Educação em Saúde com a Educação Permanente em Saúde. Entende-se a Educação em Saúde como uma potente estratégia educativa para a apropriação e empoderamento individual e coletiva sobre conhecimentos úteis para a sua saúde e qualidade de vida.

O Ministério da Saúde brasileiro define a Educação em Saúde como:

\begin{abstract}
Processo educativo de construção de conhecimentos em saúde que visa à apropriação temática pela população [...]. Conjunto de práticas do setor que contribui para aumentar a autonomia das pessoas no seu cuidado e no debate com os profissionais e os gestores a fim de alcançar uma atenção de saúde de acordo com suas necessidades (BRASIL, 2006).
\end{abstract}

Nesse contexto, as ações de educação em saúde devem envolver três atores prioritários: os profissionais de saúde que compreendam e valorizem a prevenção e a promoção assim como as práticas curativas, gestores de saúde que apoiem esses profissionais e a população que necessita desses conhecimentos para melhorar o seu processo de autocuidado (BRASIL, 2004). Na prática, essa interação é essencial para o sucesso na implementação de ações dessa natureza.

Com isto, a educação em saúde, enquanto ação estratégica no contexto da promoção da saúde e prevenção de doenças, pressupõe o desenvolvimento de pensamento crítico e reflexivo, permitindo reconhecer aspetos da realidade e propor mudanças que levem o indivíduo 
à sua autonomia e libertação enquanto sujeito social, capaz de propor e tomar decisões de saúde para cuidar de si, de sua família e de sua coletividade (SILVA et al., 2018).

Diante disto, também se reconhece a grande importância da Educação em Saúde para a consolidação do Sistema Único de Saúde e essencial para o processo de trabalho na Atenção Primária (ANDRADE, LAPOLLI, 2018). No entanto, o fato de os gestores considerarem que as ações de Educação em Saúde constituem o fazer da Educação Permanente em Saúde demonstra que estes não possuem apropriação sobre nenhuma das duas temáticas.

Isto aponta para uma forte fragilidade para a implementação da Educação Permanente em Saúde nos territórios. De acordo com as Diretrizes da Política Nacional de Educação Permanente em Saúde, os problemas de saúde devem ser identificados em cada local pelas equipes de saúde que ali atuam em conjunto com os indivíduos e famílias pertencentes a ele, o controle social e a gestão setorial (BRASIL, 2007). Para ser efetivo, esse processo deve, indispensavelmente, envolver todos estes atores.

Além disto, é de responsabilidades da gestão setorial conduzir os processos de Educação Permanente em Saúde e garantir o seguimento destes em âmbitos estaduais e federais, possibilitando que as necessidades de saúde identificadas em cada local sejam discutidas em outras instâncias (BRASIL, 2007). Quando conduzidos de forma adequada poderá-se-a, inclusive, influenciar na destinação de recursos para o desenvolvimento de ações de Educação Permanente em Saúde.

Dessa forma, a gestão participa não apenas do processo de execução das ações, mas também no planejamento, acompanhamento, monitoramento e avaliação da Educação Permanente em todos os locais que compõe o seu território.

Portanto, é de suma importância que os gestores de saúde estejam bastante apropriados em relação à Educação Permanente em Saúde em todos os aspectos. Acredita-se que isto poderá facilitar a sua tomada de decisão para a melhor condução desse processo e sua melhor implementação nos territórios. Propõe-se, então, mais momentos de capacitação e formação dos profissionais, gestores ou não, em relação à Educação na Saúde de maneira que estes desenvolvam competências para a efetiva implementação de ações de Educação Permanente em Saúde, de Educação em Saúde e outras. 
Para a equipe da Escola Técnica do SUS do Maranhão, enquanto instituição formadora no âmbito da saúde, tais achados foram extremamente relevantes, pois irão fomentar o desenvolvimento de outros processos de discussão em relação à Política Nacional de Educação Permanente em Saúde com o intuito de superar as dificuldades identificadas junto aos gestores e contribuir para o processo de implementação da Educação Permanente em Saúde.

\section{Considerações finais}

O estudo permitiu evidenciar que a concepção dos gestores de saúde em relação às práticas de educação permanente em saúde ainda é insipiente. Através das respostas, percebeu-se que eles ainda têm dificuldade na conceituação da Educação Permanente em Saúde e na diferenciação desta de outras ações do campo da Educação na Saúde, como a Educação em Saúde e a Educação Continuada.

Esses resultados são preocupantes uma vez que a Política Nacional de Educação Permanente em Saúde quando bem compreendida e, especialmente, quando é executada, promove mudanças no processo de trabalho, fortalece o Sistema Único de Saúde, favorece autonomia aos trabalhadores e, consequentemente, segurança aos usuários do SUS.

Corroborando com a preocupação, o desconhecimento dos gestores de regionais de saúde sobre essa Política desencadeia pouco empenho na implementação das ações de educação permanente, distanciando os trabalhadores de uma assistência à saúde igualitária e principalmente não executando as iniciativas do Ministério da Saúde, proporcionando mau uso de recursos públicos.

Acredita-se que o desconhecimento pode estar associado com a formação e capacitação insuficientes em relação a esta temática, principalmente quando consideramos que a Educação Permanente em Saúde foi, e ainda é, um tema pouco explorado nas Universidades e centros formadores para a saúde. Destaca-se, portanto, a necessidade de superar esta realidade e melhorar os processos de discussão desta temática ainda na academia.

Propõe-se ainda o desenvolvimento de estratégias que fomentem o reconhecimento da Educação Permanente em Saúde como estratégia para formação dos profissionais com a adoção de concepção 
pedagógica problematizadora, com o propósito de estimular a reflexão da prática e a construção do conhecimento, contribuindo para a transformação de suas práticas e, consequentemente, com o fortalecimento do Sistema Único de Saúde brasileiro.

\section{Referências}

ALCOFORADO, L. Uma educação para todos, ao longo e em todos os espaços da vida: desafios para a construção de políticas públicas promotoras de uma cidadania planetária crítica e ativa. In: SILVA, M. F. Mundos Distantes, Diálogos Possíveis: a vida em Mosaico, João Pessoa: Ideia, 2014, p. 14-34.

ALMEIDA, J. R. S. et al. Educação Permanente em Saúde: Uma estratégia para refletir sobre o processo de trabalho. Revista da Abeno, v. 16, n. 2, 2016.

ANDRADE, E. S. de; LAPOLLI, É. M. Gestão Integral: Diálogos com Educação Permanente e Continuada nas Organizações. Revista Terceiro Incluído, v. 08, 2018.

BERGER FILHO, R. L. Educação profissional no Brasil: novos rumos. Revista Iberoamericana de Educación. n. 20. 1999.

BOMFIM, E. S. et al. Educação permanente no cotidiano das equipes de saúde da família: utopia, intenção ou realidade? Cuidado é Fundamental, Rio de Janeiro, v. 9, n. 2, 2017.

BRASIL, Lei n 8.142, de 28 de dezembro de 1990. Dispõe sobre a participação da comunidade na gestão do Sistema Único de Saúde (SUS) e sobre as transferências intergovernamentais de recursos financeiros na área da saúde e dá outras providências. Diário Oficial da União: Brasília, DF, 31 dez. 1990b.

BRASIL. Constituição da República Federativa do Brasil de 1988. Emendas Constitucionais de Revisão. Brasília, DF: Senado Federal, 1988.

BRASIL. Decreto n⿳ 7.508, de 28 de junho de 2011. Regulamenta a Lei no 8.080, de 19 de setembro de 1990, para dispor sobre a organização do Sistema Único de Saúde - SUS, o planejamento da saúde, a assistência à saúde e a articulação interfederativa, e dá outras providências. Diário Oficial da União, Brasília, DF, 29 jun. 2011.. 
BRASIL. Lei $n^{\circ}$ 8.080, de 19 de setembro de 1990. Dispõe sobre as condições para a promoção, proteção e recuperação da saúde, a organização e o funcionamento dos serviços correspondentes e dá outras providências. Diário Oficial da União: Brasília, DF, 20, nov. 1990a.

BRASIL. Ministério da Saúde, Gabinete do Ministro, Portaria $\mathbf{n}^{\circ}$ 3.194, de 28 de novembro de 2017. Dispõe sobre o Programa para o Fortalecimento das Práticas de Educação Permanente em Saúde no Sistema Único de Saúde - PRO EPS-SUS. Brasília, DF, 2017b.

BRASIL. Ministério da Saúde, Gabinete do Ministro, Portaria no 1.996 de 20 de agosto de 2007. Diretrizes da Política Nacional de Educação Permanente em Saúde. Diário Oficial da União: Brasília, DF, 2007.

BRASIL. Ministério da Saúde, Gabinete do Ministro, Portaria n 198, de 13 de fevereiro de 2004. Política Nacional de Educação Permanente em Saúde como estratégia do Sistema Único de Saúde para a formação e o desenvolvimento de trabalhadores para o setor e dá outras providências. Diário Oficial da União, Brasília, DF, 2004.

BRASIL. Ministério da Saúde, Gabinete do Ministro, Portaria n².436, de 21 de setembro de 2017. Aprova a Política Nacional de Atenção Básica, estabelecendo a revisão de diretrizes para a organização da Atenção Básica, no âmbito do Sistema Único de Saúde (SUS). Brasília, DF, 2017a.

BRASIL. Ministério da Saúde, Secretaria de Gestão do Trabalho e da Educação na Saúde, Relatório consolidado sobre o processo de implementação da Política Nacional de Educação Permanente em Saúde (PNEPS). Brasília, DF, 2018b.

BRASIL. Ministério da Saúde. Educação Popular em Saúde. Participação e Controle Social.. Brasília, 2017c. Disponível em: saude. gov.br/participacao-e-controle-social/gestao-participativa-em-saude/ educacao-popular-em-saude. Acesso em: 12 maio 2020.

BRASIL. Ministério da Saúde. Secretaria de Gestão do Trabalho e da Educação na Saúde. Departamento de Gestão e da Regulação do Trabalho em Saúde. Câmara de Regulação do Trabalho em Saúde. Brasília: MS; 2006.

BRASIL. Ministério da Saúde. Secretaria de Gestão do Trabalho e da Educação na Saúde, Departamento de Gestão da Educação na Saúde. 
Planejamento das Ações de Educação Permanente em Saúde no Sistema Único de Saúde: Orientações, Brasília, DF, 2018a.

CARDOSO, Jaddh Yasmin Malta. Formação e trabalho no SUS: uma experiência de apoio institucional na cidade de Serra/ES. 2019, $138 \mathrm{f}$. Dissertação (Mestrado em Psicologia) - Universidade Federal do Espírito Santo, Vitória, 2019.

CARDOSO, M. L. M. et al. A Política Nacional de Educação Permanente em Saúde nas Escolas de Saúde Pública: reflexões a partir da prática. Ciência \& Saúde Coletiva, v. 22, n. 5, p. 1489-1500, 2017.

CAVALCANTI, F.O. L.; GUIZARDI, F. L. Educação continuada ou permanente em saúde? Análise da produção Pan-Americana da saúde. Trab. Educ. Saúde, v. 16, n.1, p. 99-122, 2018.

CECCIM, R. B.; FERLA, A. A. Educação Permanente em Saúde. Dicionário da Educação Profissional em Saúde. Fundação Oswaldo Cruz. Escola Politécnica de Saúde Joaquim Venâncio, Rio de Janeiro, 2009. Disponível em: http://www.sites.epsjv.fiocruz.br/dicionario/verbetes/edupersau. html. Acesso em: 15 jun. 2020.

DALFIOR, E. T. Análise do processo de implementação de políticas de saúde: um estudo de caso baseado no enfoque da política institucional. Saúde debate, v. 40, n. 111, out./dez. 2016.

FEUERWERKER, L. C. M. (Org). Micropolítica e saúde: produção do cuidado, gestão e formação. Porto Alegre: Rede UNIDA, 2014. 174 p. (Coleção Micropolítica do Trabalho e o Cuidado em Saúde)

FRANÇA, T. et al. Política de Educação Permanente em Saúde no Brasil: a contribuição das Comissões Permanentes de Integração Ensino-Serviço. Ciênc. Saúde Colet, v. 22, n. 6, jun. 2017.

JUNIOR, S. R. A. M.; ROCHA, K. C. R.; FERRONATO, C. J. Reflexões sobre a Educação em Saúde no Brasil: uma Revisão Integrativa. In: ENCONTRO INTERNACIONAL DE FORMAÇÃO DE PROFESSORES, 11, 2018, Aracaju. Anais eletrônico [...] Aracaju: ITP, 2018. Disponível em: https://eventos. set.edu.br/index.php/enfope/article/viewFile/8792/3742. Acesso em: 20 mar. 2020.

KRÜGER, C. et al. Análise das políticas públicas para o desenvolvimento da faixa de fronteira brasileira. Ambiente $\&$ Sociedade, São Paulo, v. 20, n. 4, p. 41-62, out./dez. 2017. 
LEMOS, C. L. S. Educação Permanente em Saúde no Brasil: educação ou gerenciamento permanente? Ciênc. Saúde Colet, v. 21, n. 3, mar. 2016. LIMA, L. P. S.; RIBEIRO, M. R. R. A competência para Educação Permanente em Saúde: percepções de coordenadores de graduações da saúde. Physis Revista de Saúde Coletiva, Rio de Janeiro, v. 26, n. 2, p. 483-501, 2016.

MACHADO, C. V.; LIMA, L. D. de; BAPTISTA, W. F. Políticas de saúde no Brasil em tempos contraditórios: caminhos e tropeços na construção de um sistema universal. Cad. Saúde Pública, Rio de Janeiro, v. 33, sup. 2, out. 2017.

MARANHÃO. Decreto $n^{\circ} 20.217$, de 31 de dezembro de 2003. Criação da Escola Técnica do SUS "Dra. Maria Nazareth Ramos de Neiva". Diário Oficial do Estado do Maranhão, Poder Executivo, São Luís, MA, 2003.

MARANHÃO. Projeto Político Pedagógico. Escola Técnica do “Dra. Maria Nazareth Ramos de Neiva", São Luís, MA, 2012.

MARQUES, M. et al.. A importância da educação continuada na socialização do novo profissional de enfermagem Revista Inova Saúde, Criciúma, v. 8, n. 2, 2018.

MERHY. Reflexões sobre o Sistema Único de Saúde: inovações e limites. Revista do Serviço Público, Brasília, p. 123-132, 2007.

SILVA, J. P. et al. Promoção da saúde na educação básica: percepções dos alunos de licenciatura em enfermagem. Revista Gaúcha de Enfermagem, Porto Alegre, v.39, 03 set. 2018.

VENDRUSCOLO, C. et al. Integração ensino-serviço em saúde: diálogos possíveis a partir da cogestão de coletivos. Esc Anna Nery, v. 22, n. 4, 2018.

Recebido em: Maio/2020

Aceito em: Julho/2020 